\title{
Hematological, Micro-Rheological, and Metabolic Changes Modulated by Local Ischemic Pre- and Post-Conditioning in Rat Limb Ischemia-Reperfusion
}

\author{
Csaba Korei ${ }^{1,2,3}$, Balazs Szabo ${ }^{2,3}$, Adam Varga ${ }^{2,3}$, Barbara Barath ${ }^{2,3}$, Adam Deak ${ }^{2}$, Erzsebet Vanyolos ${ }^{2}$, \\ Zoltan Hargitai ${ }^{4}$, Ilona Kovacs ${ }^{4}$, Norbert Nemeth ${ }^{2, * \mathbb{D}}$ and Katalin Peto ${ }^{2}$ \\ 1 Department of Traumatology and Hand Surgery, Faculty of Medicine, University of Debrecen, \\ Bartok Bela ut 2-26, H-4031 Debrecen, Hungary; korei.csaba@med.unideb.hu \\ 2 Department of Operative Techniques and Surgical Research, Faculty of Medicine, University of Debrecen, \\ Moricz Zsigmond u. 22, H-4002 Debrecen, Hungary; balazsszabo929@gmail.com (B.S.); \\ varga.adam@med.unideb.hu (A.V.); barath.barbara@med.unideb.hu (B.B.); \\ deak.adam@med.unideb.hu (A.D.); vanyolos@med.unideb.hu (E.V.); kpeto@med.unideb.hu (K.P.) \\ 3 Doctoral School of Clinical Medicine, University of Debrecen, Nagyerdei krt. 98, H-4032 Debrecen, Hungary \\ 4 Clinical Center, Pathology Unit, Kenezy Campus, University of Debrecen, Bartok Bela ut 2-26, \\ H-4031 Debrecen, Hungary; z.hargy@gmail.hu (Z.H.); dr.kovacs.ilona@kenezy.unideb.hu (I.K.) \\ * Correspondence: nemeth@med.unideb.hu; Tel./Fax: +36-52-416-915
}

\section{check for} updates

Citation: Korei, C.; Szabo, B.; Varga, A.; Barath, B.; Deak, A.; Vanyolos, E.; Hargitai, Z.; Kovacs, I.; Nemeth, N.; Peto, K. Hematological,

Micro-Rheological, and Metabolic Changes Modulated by Local Ischemic Pre- and Post-Conditioning in Rat Limb Ischemia-Reperfusion. Metabolites 2021, 11, 776. https:// doi.org/10.3390/metabo11110776

Academic Editor: Amedeo Lonardo

Received: 26 October 2021

Accepted: 11 November 2021

Published: 13 November 2021

Publisher's Note: MDPI stays neutral with regard to jurisdictional claims in published maps and institutional affiliations.

Copyright: (c) 2021 by the authors. Licensee MDPI, Basel, Switzerland. This article is an open access article distributed under the terms and conditions of the Creative Commons Attribution (CC BY) license (https:/ / creativecommons.org/licenses/by/ $4.0 /)$.
Abstract: In trauma and orthopedic surgery, limb ischemia-reperfusion (I/R) remains a great challenge. The effect of preventive protocols, including surgical conditioning approaches, is still controversial. We aimed to examine the effects of local ischemic pre-conditioning (PreC) and post-conditioning (PostC) on limb I/R. Anesthetized rats were randomized into sham-operated (control), I/R (120-min limb ischemia with tourniquet), PreC, or PostC groups $(3 \times 10$-min tourniquet ischemia, 10-min reperfusion intervals). Blood samples were taken before and just after the ischemia, and on the first postoperative week for testing hematological, micro-rheological (erythrocyte deformability and aggregation), and metabolic parameters. Histological samples were also taken. Erythrocyte count, hemoglobin, and hematocrit values decreased, while after a temporary decrease, platelet count increased in I/R groups. Erythrocyte deformability impairment and aggregation enhancement were seen after ischemia, more obviously in the PreC group, and less in PostC. Blood pH decreased in all I/R groups. The elevation of creatinine and lactate concentration was the largest in PostC group. Histology did not reveal important differences. In conclusion, limb I/R caused micro-rheological impairment with hematological and metabolic changes. Ischemic pre- and post-conditioning had additive changes in various manners. Post-conditioning showed better micro-rheological effects. However, by these parameters it cannot be decided which protocol is better.

Keywords: limb ischemia-reperfusion; hemorheology; metabolites; ischemic pre-conditioning; ischemic post-conditioning

\section{Introduction}

Acute limb ischemia still remains a great challenge in clinical practice. In connection with traumatic injuries, vascular and orthopedic surgery the blood supply to the limbs is often impaired or temporarily stopped (hypoperfusion, ischemia), resulting in ischemiareperfusion (I/R) injury associated with significant morbidity and mortality [1-4]. The incidence is estimated at 1.5 cases per 10,000 people [1]. The I/ $R$ injury is also a major problem in emergency care. It is very important to reduce the time of ischemia to prevent further organ damage. Indirect tissue damage may be exacerbated by shock or resuscitation. Post-cardiac arrest syndrome can also be considered part of systemic I/R injury, which leads to organ and brain failure, death. Systemic ischemia is associated with hypoxia and a lack of energy at the tissue and cellular level. In case of contradictory but successful 
resuscitation, recurrent circulation may further aggravate organ failure [4-6]. Repeated periods of ischemia and reperfusion may also cause wound healing disorders [7].

It is essential to restore circulation as soon as possible within the ischemic tolerance time of the given organ or tissue. The critical ischemic time for human muscle tissue is about $2.25 \mathrm{~h}$ in warm ischemia, and irreversible muscle damage starts after $3 \mathrm{~h}$ of ischemia and is nearly complete at $6 \mathrm{~h}[8,9]$. The restoration of blood supply can further aggravate the ischemic damage and results in endothelial and parenchymal injury, referred to as I/R injury. The etiological factors include $\mathrm{Ca}^{2+}$ overload, oxidative stress, leukocyte infiltration, release of inflammatory mediators, endothelial dysfunction, and complement activation [9-11].

To prevent or reduce I/R injury, considerable effort has been made in developing various therapeutic strategies, including pharmacological and surgical approaches [3,4]. A simple strategy is hypothermia and the use of chilled heparin saline [6]. During surgeries, I/R damage can be reduced by graduate reperfusion [12]. Ischemic pre-conditioning has emerged as a powerful experimental method in decreasing ischemic injury by Murry et al. in 1986 in canine myocardium [13]. The method consists of inducing brief ischemic insults to the target organ before the subsequent prolonged ischemia. Its beneficial effect was proven in several organs and tissues $[14,15]$. However, the clinical application is limited due to the unpredictable onset of an ischemic insult or embolic event. A further development of the method is the remote ischemic pre-conditioning, which was described by Przyklenk in 1993 [16]. It can increase the tolerance against I/R injury in many organs, involving the brain, heart, and kidney [17]. It is based on intermittent short-term interruptions of the blood flow of another organ or extremity before the ischemic period of the target organ. The limitation of the method is that it can be applied only in case of elective interventions. The mechanism of post-conditioning was introduced by Zhao et al. [18]. In contrast to pre-conditioning, the brief periods of ischemia and reperfusion are applied at the onset of the reperfusion, after the target organ ischemia. This technique can be easily applied to the ischemic tissue after the surgery.

The red blood cell deformability and aggregation show significant changes in many pathophysiological conditions. Ischemia-reperfusion injury may cause micro-rheological changes due to metabolic changes, free radical reactions, and acute phase reactions [19-21]. Although a huge number of studies have examined the consequences of I/R injury to skeletal muscle and the protective effect of pre- and post-conditioning [22-24], very few studies have addressed the changes in the micro-rheological parameters [25,26].

In our previous studies, we have found significant alterations in blood rheological parameters due to limb ischemia and reperfusion, however, the magnitude of changes was different. The most obvious alterations were found after $3 \mathrm{~h}$ of ischemia (vascular clamp combined with tourniquet) that led to histological changes and rheological deterioration together. The morphological changes could be sustained by local cooling, but not the rheological ones [27]. In rat models of 1- and 2-h ischemia and following reperfusion, microrheological deterioration was found in the early reperfusion period (the first hour of reperfusion) and in a second wave on the first to third postoperative days $[28,29]$. The time factor is important, depending on the ischemic tolerance of the tissues. The skin and muscles are known to have relatively wide ischemic tolerance. However, it is important to note that the endothelium is very sensitive to hypoxia, and endothelial dysfunction may occur in a short time. Kayar et al. found that even $15 \mathrm{~min}$ of ischemia may lead to endothelial dysfunction and rheological alterations in rats [19]. So, the picture is very complex and it is not clear where the boundary of reversible and irreversible changes is. It is not known how large hemorheological change leads to a perfusion problem, and how depressed should the perfusion be to result in further changes in the tissues, not talking about the duration, temperature, and extension of complete ischemia.

The present study was therefore designed to evaluate the alterations in the hematological and micro-rheological parameters due to lower limb ischemia and to compare the expected favorable effect of pre- and post-conditioning in a rat model. 


\section{Results}

\subsection{Hematological Parameters}

Hematological parameters are shown in Table 1. The white blood cell count increased just after the 120-min ischemia in the I/R ( $p=0.018$ vs. base) and in the PreC groups $(p<0.001$ vs. base) and was elevated further by the end of the first postoperative (p.o.) week, reaching a significant level in the PreC ( $p<0.001$ vs. base) and the PostC groups $(p=0.008$ vs. base).

Table 1. Selected hematological parameters in the control, the ischemia-reperfusion (I/R), the ischemic pre-conditioning (PreC), and the ischemic post-conditioning (PostC) groups.

\begin{tabular}{|c|c|c|c|c|}
\hline Variable & Group & Base & Reperfusion & 1st p.o. Week \\
\hline \multirow{4}{*}{ WBC [G/L] } & Control & $9.36 \pm 1.85$ & $8.62 \pm 2.35$ & $10.4 \pm 3.59$ \\
\hline & $\mathrm{I} / \mathrm{R}$ & $8.05 \pm 1.23$ & $10.77 \pm 4.23$ * & $10.17 \pm 4.47$ \\
\hline & PreC & $7.08 \pm 1.11$ & $10.67 \pm 2.53 *$ & $11.2 \pm 4.15^{*}$ \\
\hline & PostC & $7.51 \pm 1.57$ & $8.77 \pm 3.67$ & $10.65 \pm 3.1 *$ \\
\hline \multirow{4}{*}{$\mathrm{RBC}[\mathrm{T} / \mathrm{L}]$} & Control & $7.78 \pm 0.47$ & $7.49 \pm 0.41$ & $7.44 \pm 0.37$ \\
\hline & $\mathrm{I} / \mathrm{R}$ & $8.38 \pm 0.64$ & $7.69 \pm 0.71 *$ & $7.09 \pm 0.28^{*}$ \\
\hline & PreC & $8.35 \pm 0.39$ & $7.65 \pm 0.56^{*}$ & $6.93 \pm 1.37^{*}$ \\
\hline & PostC & $8.18 \pm 0.73$ & $7.69 \pm 0.77$ & $7.09 \pm 0.43$ * \\
\hline \multirow{4}{*}{$\mathrm{Hgb}[\mathrm{g} / \mathrm{dL}]$} & Control & $15.23 \pm 0.74$ & $14.89 \pm 0.67$ & $14.52 \pm 0.83 *$ \\
\hline & $\mathrm{I} / \mathrm{R}$ & $15.61 \pm 0.82$ & $14.75 \pm 0.76^{*}$ & $13.41 \pm 0.51 *$ \\
\hline & PreC & $15.18 \pm 0.41$ & $14.14 \pm 0.79$ * & $12.84 \pm 2.56^{*}$ \\
\hline & PostC & $15.16 \pm 0.68$ & $14.25 \pm 0.84$ * & $13.25 \pm 0.78 * \#$ \\
\hline \multirow{4}{*}{ Hct $[\%]$} & Control & $46.68 \pm 2.45$ & $45.23 \pm 2.43$ & $43.6 \pm 2.07^{*}$ \\
\hline & $\mathrm{I} / \mathrm{R}$ & $47.4 \pm 3.07$ & $44.6 \pm 3.49$ & $40.39 \pm 1.31$ * \# \\
\hline & PreC & $46.7 \pm 1.41$ & $43.81 \pm 2.99$ & $38.96 \pm 7.56^{*}$ \\
\hline & PostC & $45.93 \pm 2.87$ & $44.13 \pm 3.16$ & $40.21 \pm 2.09 * \#$ \\
\hline \multirow{4}{*}{ Plt [G/L] } & Control & $741.2 \pm 62.1$ & $626.8 \pm 99.5^{*}$ & $833.6 \pm 40.9 *$ \\
\hline & $\mathrm{I} / \mathrm{R}$ & $810.1 \pm 72.9$ & $747.6 \pm 80.5^{*} \#$ & $958.5 \pm 100.1$ * \# \\
\hline & PreC & $726.3 \pm 82.7$ & $638.3 \pm 63 *$ & $873.1 \pm 315.4^{*}$ \\
\hline & PostC & $712.6 \pm 67.2$ & $625.7 \pm 57.2 *$ & $1000 \pm 44.5 * \#$ \\
\hline
\end{tabular}

Means \pm S.D.; $*<0.05$ vs. base (same group), \# $p<0.05$ vs. control group (same time); RBC: red blood cell count; WBC: white blood cell count; Hgb: hemoglobin concentration; Hct: hematocrit; Plt: platelet count.

Red blood cell count, hemoglobin, and hematocrit values showed a moderate decrease at the beginning of the reperfusion versus base values (RBC in I/R group: $p=0.021$, in PreC group: $p<0.001$; Hgb in I/R group: $p=0.009$, in PreC group: $p<0.001$, in PostC group: $p=0.004$ ). A further decrease was observed by the first $p$.o. week (RBC, Hgb and Hct in $\mathrm{I} / \mathrm{R}$, PreC and PostC groups: $p<0.001)$. In the PostC groups, reduction of hemoglobin and hematocrit ( $p=0.001$ for both), as well as hematocrit decrease in I/R group was found to be significant compared to the Control group $(p<0.001)$.

Platelet count showed lower values after the 120-min ischemia compared to base values (Control: $p<0.001, \mathrm{I} / \mathrm{R}: p=0.041$, PreC: $p=0.002$, PostC: $p=0.001$ ), and rose by the first p.o. week (Control: $p<0.001$, I/R: $p<0.001$, PreC: $p=0.032$, PostC: $p<0.001$ ). The values of the I/R group were higher versus the Control group at the beginning of the reperfusion $(p=0.002)$ and on the first p.o. week $(p=0.006)$. The highest values were found in the PostC group one week after surgery $(p<0.001$ vs. Control). 


\subsection{Red Blood Cell Deformability}

The cumulative elongation index (EI)—shear stress (SS) curves are shown on Figure 1, the comparative parameterization data are summarized in Table 2.

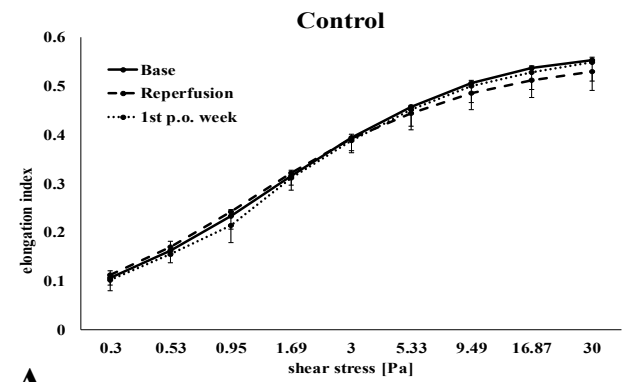

A

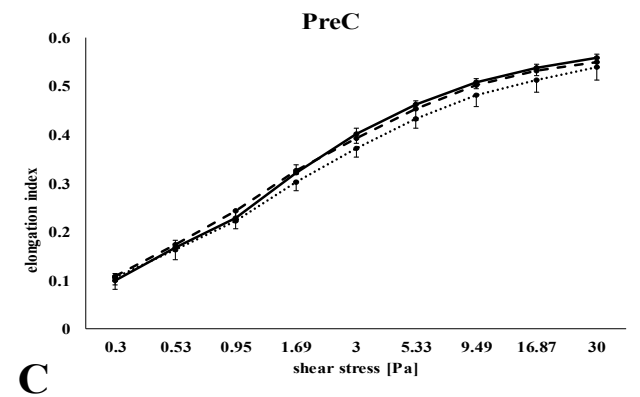

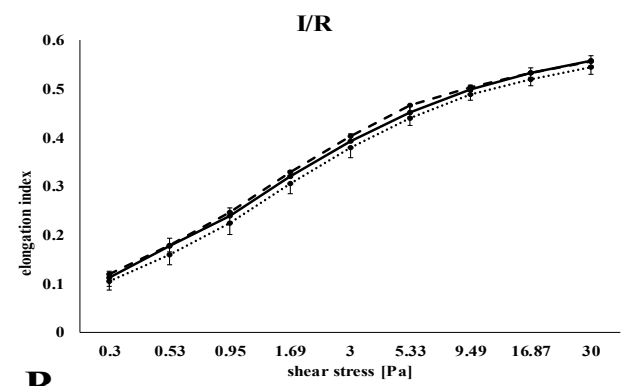

B

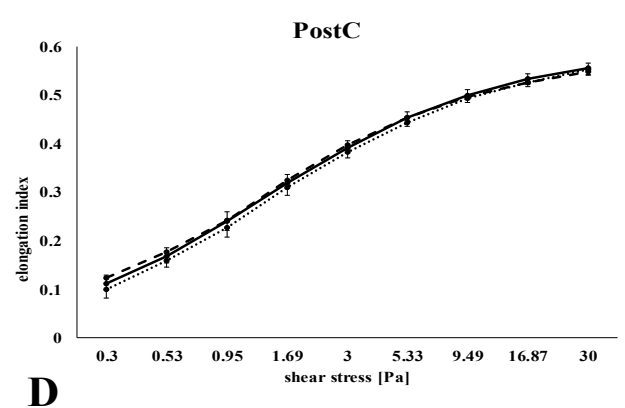

Figure 1. Changes of red blood cell deformability (elongation index in the function of shear stress in the control (A), the ischemia-reperfusion $(\mathrm{I} / \mathrm{R})(\mathbf{B})$, the ischemic pre-conditioning $(\mathrm{PreC})(\mathbf{C})$ and the ischemic post-conditioning (PostC) $(\mathrm{D})$ groups. Means \pm S.D.

Table 2. Erythrocyte deformability values delivered from the elongation index (EI): shear stress (SS) curves in the control, the ischemia-reperfusion (I/R), the ischemic pre-conditioning (PreC), and the ischemic post-conditioning (PostC) groups.

\begin{tabular}{ccccc}
\hline Variable & Group & Base & Reperfusion & 1st p.o. Week \\
\hline & Control & $0.393 \pm 0.007$ & $0.392 \pm 0.024$ & $0.387 \pm 0.01$ \\
EI at 3 Pa & I/R & $0.392 \pm 0.013$ & $0.402 \pm 0.009$ & $0.378 \pm 0.02 *$ \\
& PreC & $0.400 \pm 0.012$ & $0.392 \pm 0.012$ & $0.371 \pm 0.018$ \\
& PostC & $0.391 \pm 0.013$ & $0.397 \pm 0.01$ & $0.382 \pm 0.012$ \\
& Control & $0.582 \pm 0.015$ & $0.553 \pm 0.049$ & $0.571 \pm 0.017$ \\
$\mathrm{EI}_{\max }$ & $\mathrm{I} / \mathrm{R}$ & $0.601 \pm 0.02$ & $0.587 \pm 0.022$ & $0.581 \pm 0.032$ \\
& PreC & $0.585 \pm 0.019$ & $0.589 \pm 0.024$ & $0.588 \pm 0.046$ \\
& PostC & $0.595 \pm 0.028$ & $0.576 \pm 0.023$ & $0.593 \pm 0.022$ \\
$\mathrm{SS}_{1 / 2}[\mathrm{~Pa}]$ & Control & $1.44 \pm 0.25$ & $1.2 \pm 0.42$ & $1.53 \pm 0.3$ \\
& I/R & $1.23 \pm 0.33$ & $1.26 \pm 0.25$ & $1.45 \pm 0.27$ \\
& PreC & $1.36 \pm 0.25$ & $1.21 \pm 0.23$ & $1.33 \pm 0.52$ \\
$\mathrm{EI}_{\max } / \mathrm{SS}_{1 / 2}\left[\mathrm{~Pa}^{-1}\right]$ & PostC & $1.28 \pm 0.46$ & $1.32 \pm 0.36$ & $1.34 \pm 0.25$ \\
& Control & $0.419 \pm 0.092$ & $0.52 \pm 0.19$ & $0.387 \pm 0.087$ \\
& I/R & $0.524 \pm 0.156$ & $0.488 \pm 0.136$ & $0.418 \pm 0.112$ \\
& PreC & $0.454 \pm 0.143$ & $0.499 \pm 0.096$ & $0.553 \pm 0.365$ \\
& PostC & $0.487 \pm 0.223$ & $0.473 \pm 0.165$ & $0.458 \pm 0.103$ \\
\hline
\end{tabular}

Means \pm S.D.; ${ }^{*} p<0.05$ vs. base (same group); $\mathrm{EI}_{\max }$ : maximal EI; $\mathrm{SS}_{1 / 2}$ : shear stress at half $\mathrm{EI}_{\max }$.

The EI values were lower one week after surgery in the I/R group, and more obviously in the PreC group (Figure 1B,C). However, the differences were small. By the 1st p.o. week EI values at 3 Pa showed significant lowering in the I/R group compared to their base $(p=0.048)$. When analyzing the changes compared to base values, individually, these relative values revealed more differences (Figure 2). The magnitude of lowering in EI at 3 Pa was significant one week after surgery compared to the post-ischemic relative values 
(Control: $p=0.012, \mathrm{I} / \mathrm{R}: p=0.005$, PreC: $p=0.025$ ). The rise in $\mathrm{SS}_{1 / 2}$ was the highest in the $\mathrm{I} / \mathrm{R}$ group, which was reflected in the $\mathrm{EI}_{\max } / \mathrm{SS}_{1 / 2}$ ratio $(p=0.002)$ (Figure 2).
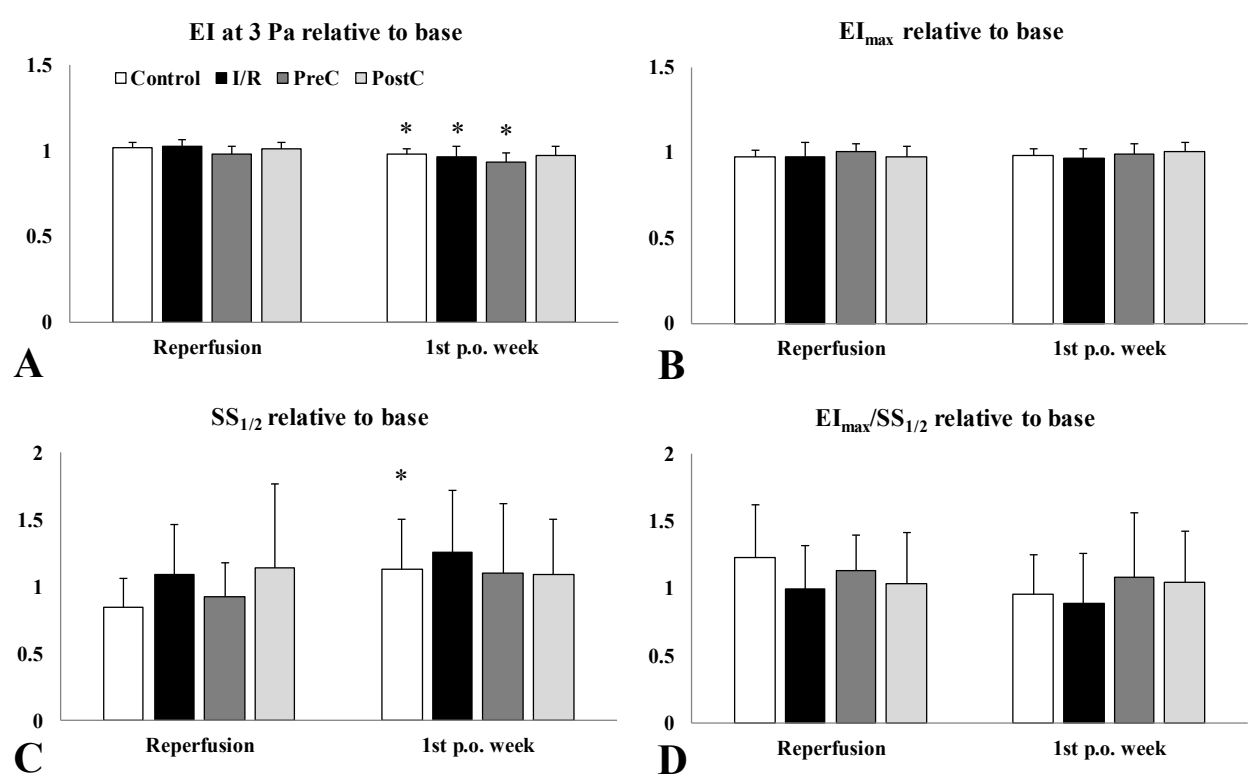

Figure 2. Relative values of elongation index (EI) at $3 \mathrm{~Pa}(\mathrm{~A})$, maximal elongation index $\left(\mathrm{EI}_{\max }\right)(\mathbf{B})$, shear stress at half $\mathrm{EI}_{\max }\left(\mathrm{SS}_{1 / 2}\right)(\mathbf{C})$, and the ratio of $\mathrm{EI}_{\max }$ and $\mathrm{SS}_{1 / 2}(\mathrm{D})$, compared to their base values (as 100\%) in the control, the ischemia-reperfusion (I/R), the ischemic pre-conditioning (PreC) and the ischemic post-conditioning (PostC) groups. Means \pm S.D., ${ }^{*} p<0.05$ vs. reperfusion.

\subsection{Red Blood Cell Aggregation}

Enhanced red blood cell aggregation was found in the ischemic groups (I/R, PreC, PostC) one week after surgery, showing increased M and M1 index values (Figure 3). The $\mathrm{I} / \mathrm{R}$ and PreC groups expressed the highest values of M $5 \mathrm{~s}$ ( $p<0.001$ vs. base for both), M1 5s (only in PreC group: $p=0.038$ vs. base and $p=0.046$ vs. Control), as well as in M 10s $(p<0.001$ vs. base for both) and M1 10s index values ( $p<0.001$ vs. base for both) (Figure 3).

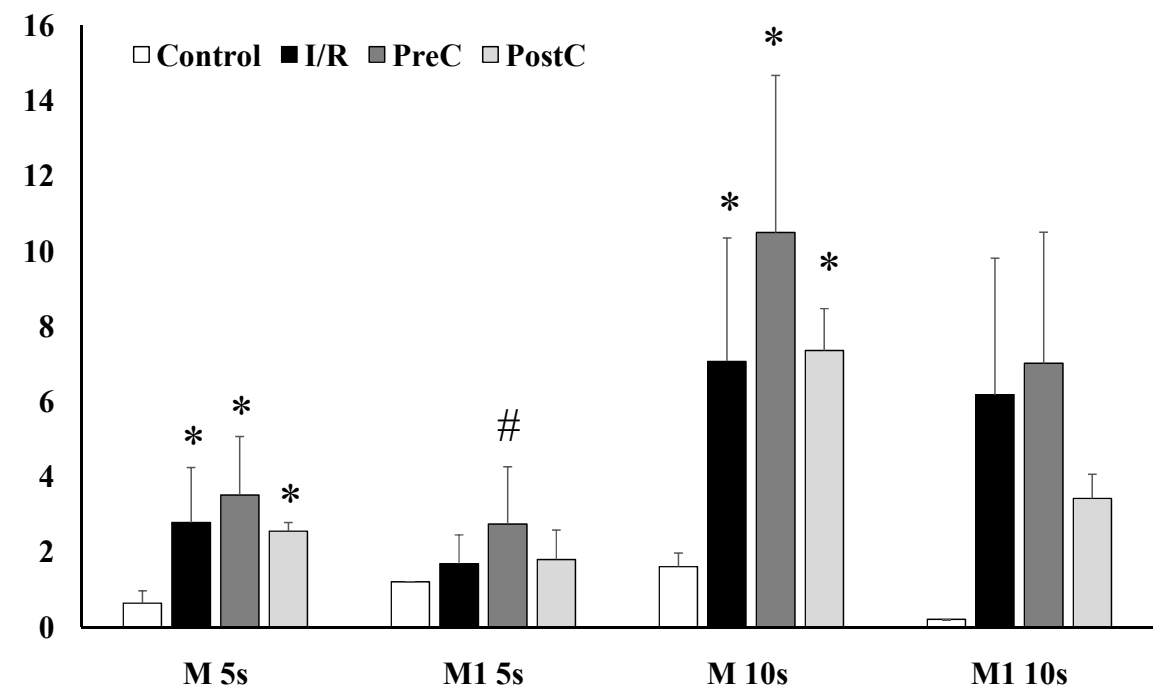

Figure 3. Red blood cell aggregation index values (M 5s, M1 5s, M 10s, M1 10s) in the control, the ischemia-reperfusion (I/R), the ischemic pre-conditioning (PreC), and the ischemic postconditioning (PostC) groups on the first postoperative week. Means \pm S.D., ${ }^{*} p<0.05$ vs. Control group and $\# p<0.05$ vs. I/R group (same time). 


\subsection{Blood Gases, Acid-Base Parameters, Electrolytes, and Metabolites}

Table 3 summarizes the changes of blood gas, $\mathrm{pH}$, electrolyte, and metabolic parameters.

Table 3. Changes of blood gas $\left(p \mathrm{O}_{2}, p \mathrm{CO}_{2}\right), \mathrm{pH}$, electrolytes $\left(\mathrm{Na}^{+}, \mathrm{K}^{+}, \mathrm{Ca}^{2+}, \mathrm{Cl}^{-}\right.$,) and metabolites (glucose, lactate, creatinine) in the control, the ischemia-reperfusion (I/R), the ischemic pre-conditioning (PreC), and the ischemic postconditioning (PostC) groups.

\begin{tabular}{|c|c|c|c|c|}
\hline Variable & Group & Base & Reperfusion & 1st p.o. Week \\
\hline \multirow{4}{*}{$p \mathrm{O}_{2}[\mathrm{mmHg}]$} & Control & $68.87 \pm 13.26$ & $65.73 \pm 11.05$ & $55.2 \pm 6.93$ \\
\hline & $\mathrm{I} / \mathrm{R}$ & $60.14 \pm 6.61$ & $61.37 \pm 8.49$ & $55.06 \pm 9.22$ \\
\hline & PreC & $65.05 \pm 5.75$ & $69.47 \pm 15.27$ & $51.78 \pm 11.8$ \\
\hline & PostC & $59.65 \pm 9.27$ & $68.08 \pm 6.57$ & $57.1 \pm 16.21$ \\
\hline \multirow{4}{*}{$p \mathrm{CO}_{2}[\mathrm{mmHg}]$} & Control & $41.3 \pm 9.04$ & $43.55 \pm 5.54$ & $52.62 \pm 11.23$ \\
\hline & I/R & $50.45 \pm 6.57$ & $49.94 \pm 17.77$ & $49.4 \pm 4.72$ \\
\hline & PreC & $47.64 \pm 6.78$ & $48.01 \pm 11.17$ & $42.42 \pm 4.95$ \\
\hline & PostC & $47.78 \pm 6.62$ & $47.68 \pm 12.2$ & $45.12 \pm 5.86$ \\
\hline \multirow{4}{*}{$\mathrm{pH}$} & Control & $7.41 \pm 0.03$ & $7.37 \pm 0.03$ & $7.36 \pm 0.06$ \\
\hline & $\mathrm{I} / \mathrm{R}$ & $7.36 \pm 0.04$ & $7.33 \pm 0.11$ & $7.38 \pm 0.04$ \\
\hline & PreC & $7.38 \pm 0.07$ & $7.31 \pm 0.07$ & $7.41 \pm 0.04$ \\
\hline & PostC & $7.35 \pm 0.03$ & $7.32 \pm 0.08$ & $7.39 \pm 0.02$ \\
\hline \multirow{4}{*}{$\mathrm{Na}^{+}[\mathrm{mmol} / \mathrm{L}]$} & Control & $142.12 \pm 3.35$ & $141.83 \pm 2.13$ & $143.6 \pm 2.61$ \\
\hline & $\mathrm{I} / \mathrm{R}$ & $141 \pm 2.31$ & $140.28 \pm 5.4$ & $142 \pm 2.34$ \\
\hline & PreC & $142.28 \pm 2.69$ & $140.28 \pm 4.46$ & $141.71 \pm 2.56$ \\
\hline & PostC & $142.42 \pm 3.2$ & $140.14 \pm 2.47$ & $143.85 \pm 2.41$ \\
\hline \multirow{4}{*}{$\mathrm{K}^{+}[\mathrm{mmol} / \mathrm{L}]$} & Control & $4.72 \pm 0.32$ & $5.45 \pm 0.56^{*}$ & $4.82 \pm 0.29$ \\
\hline & $\mathrm{I} / \mathrm{R}$ & $4.32 \pm 0.28$ & $5.92 \pm 0.57 *$ & $4.04 \pm 0.38 \#$ \\
\hline & PreC & $4.25 \pm 0.25$ & $5.58 \pm 0.86^{*}$ & $4.61 \pm 0.5$ \\
\hline & PostC & $4.24 \pm 0.25$ & $6.05 \pm 0.62 *$ & $4.17 \pm 0.29 \#$ \\
\hline \multirow{4}{*}{$\mathrm{Ca}^{2+}[\mathrm{mmol} / \mathrm{L}]$} & Control & $1.36 \pm 0.04$ & $1.38 \pm 0.11$ & $1.28 \pm 0.19$ \\
\hline & $\mathrm{I} / \mathrm{R}$ & $1.35 \pm 0.04$ & $1.39 \pm 0.04$ & $1.23 \pm 0.31$ \\
\hline & PreC & $1.34 \pm 0.06$ & $1.39 \pm 0.06$ & $1.27 \pm 0.17$ \\
\hline & PostC & $1.39 \pm 0.05$ & $1.39 \pm 0.03$ & $1.32 \pm 0.09$ \\
\hline \multirow{4}{*}{$\mathrm{Cl}^{-}[\mathrm{mmol} / \mathrm{L}]$} & Control & $104.25 \pm 1.67$ & $108.16 \pm 3.18$ & $104.6 \pm 1.34$ \\
\hline & $\mathrm{I} / \mathrm{R}$ & $103.14 \pm 2.11$ & $105.85 \pm 2.19$ & $102.6 \pm 1.67$ \\
\hline & PreC & $103.14 \pm 2.03$ & $104.85 \pm 2.79$ & $104 \pm 1.52$ \\
\hline & PostC & $104 \pm 2.31$ & $106.28 \pm 1.6$ & $103.85 \pm 2.19$ \\
\hline \multirow{4}{*}{ glucose [mmol/L] } & Control & $19.62 \pm 3.54$ & $17.11 \pm 3.47$ & $17.94 \pm 3.08$ \\
\hline & $\mathrm{I} / \mathrm{R}$ & $17.98 \pm 2.09$ & $19.6 \pm 4.27$ & $12.34 \pm 2.21 * \#$ \\
\hline & PreC & $17.22 \pm 2.19$ & $22.48 \pm 7.61$ & $11.8 \pm 2.61 * \#$ \\
\hline & PostC & $16.5 \pm 1.09$ & $22.64 \pm 4.77$ *\# & $13.12 \pm 2.45^{*} \#$ \\
\hline \multirow{4}{*}{ lactate $[\mathrm{mmol} / \mathrm{L}]$} & Control & $1.171 \pm 0.34$ & $1.52 \pm 0.61$ & $1.02 \pm 0.32$ \\
\hline & $\mathrm{I} / \mathrm{R}$ & $1.61 \pm 0.73$ & $1.36 \pm 0.34$ & $2.31 \pm 0.91 \#$ \\
\hline & PreC & $1.78 \pm 0.87$ & $1.72 \pm 0.85$ & $3.11 \pm 1.89 \#$ \\
\hline & PostC & $1.82 \pm 0.99$ & $1.28 \pm 0.31$ & $3.39 \pm 2.2 \#$ \\
\hline \multirow{4}{*}{ creatinine $[\mu \mathrm{mol} / \mathrm{L}]$} & Control & $31 \pm 4.37$ & $43.83 \pm 10$ & $36.2 \pm 3.89$ \\
\hline & $\mathrm{I} / \mathrm{R}$ & $35.33 \pm 5.68$ & $47.85 \pm 8.47$ & $37.2 \pm 5.26$ \\
\hline & PreC & $32.42 \pm 3.59$ & $68.42 \pm 31.28 *$ & $52.85 \pm 25.51$ \\
\hline & PostC & $43.85 \pm 8.45$ & $83 \pm 43.77^{*} \#+$ & $35.71 \pm 6.15$ \\
\hline
\end{tabular}

Means \pm S.D.; ${ }^{*} p<0.05$ vs. base (the same group), $\# p<0.05$ vs. Control group and $+p<0.05$ vs. I/R group (at the same time).

The values of $p \mathrm{O}_{2}, p \mathrm{CO}_{2}$ did not change significantly. The $\mathrm{pH}$ decreased in the PreC and PostC groups at the start of the reperfusion and normalized by the first p.o. week.

Sodium, calcium, and chloride ion concentrations did not show significant changes. Just after the ischemia, the potassium ion concentration increased significantly in all groups versus the base, with larger magnitude in the groups subjected to ischemia (Control: $p=0.01$, I/R: $p<0.001$, PreC: $p=0.011$, PostC: $p<0.001$ vs. base). By the first p.o. week, the potassium concentration was lower in $\mathrm{I} / \mathrm{R}$ and in Post $\mathrm{C}$ groups compared to the Control ( $p=0.007$ and $p=0.004$, respectively). 
An increase was observed in the glucose concentration in all groups with ischemia and reperfusion. The rise was significant in the PostC group ( $p=0.002$ vs. base, $p=0.039$ vs. Control). By the first p.o. week these values significantly decreased in these groups compared to base (I/R: $p=0.001$, PreC: $p=0.001$, PostC: $p=0.006$ ) and compared to the Control group (I/R: $p=0.01$, PreC: $p=0.004$, PostC: $p=0.013$ ). Lactate concentration increased significantly by the first p.o. week in the I/R $(p=0.019), \operatorname{PreC}(p=0.037)$ and PostC ( $p=0.041)$ groups compared to the Control. Creatinine concentration increased significantly only in the PreC ( $p=0.002$ vs. base) and PostC ( $p=0.017$ vs. base, $p=0.008$ vs. Control, $p=0.038$ vs. I/R) groups just after the reperfusion.

\subsection{Histology}

No histological abnormalities attributable to ischemia were seen in any of the groups by light microscopy (Figure 4). Analyzing the postoperative samples preserved striation, regular contour of the muscle fibers was found with the normal distribution of the nuclei without any sign of hypertrophy. No disorganization of myofibrils occurred in the sarcoplasm. Swelling and intense inflammatory infiltration could not be demonstrated. Necrotic muscle fiber sections were not present and no caliber fluctuation was detected. In a pre-conditioned animal, signs of subacute inflammation and fresh bleeding were seen in the perimysium, which may have developed due to the tourniquet compression.
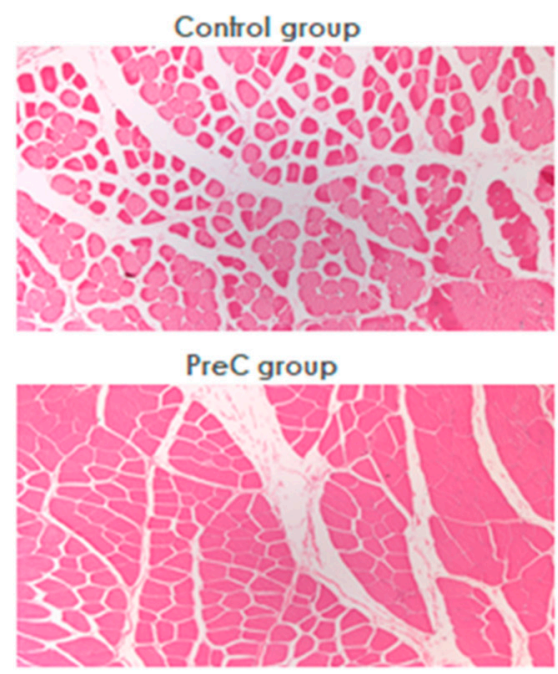

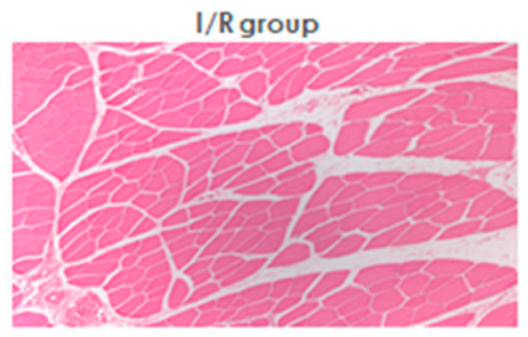

PostC group

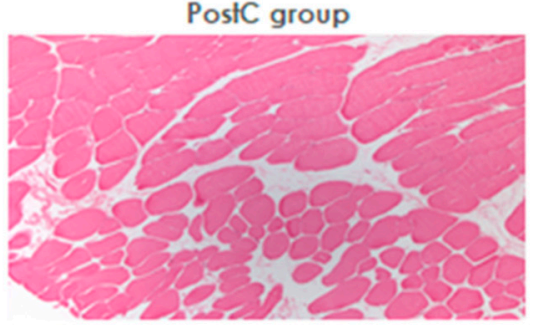

Figure 4. Representative histological slides of the skeletal muscle biopsies in the control, the ischemiareperfusion (I/R), the ischemic pre-conditioning (PreC), and the ischemic post-conditioning (PostC) groups. Staining: H\&E; original magnification: $50 \times$.

\section{Discussion}

The tourniquet is used in many areas of surgery, such as traumatology, orthopedics, and vascular surgery. In experimental studies, several strategies have been developed to reduce I/R injury, but very few of them have been introduced into clinical practice. Among surgical approaches, pre- and post-conditioning are promising methods [13-18], although there are still many unanswered questions involving the optimal timing of the stimulus and the number and duration of the cycles, etc. It should also be taken into account that the applicability of pre-conditioning in clinical practice is limited to scheduled surgery, while ischemic post-conditioning can be easily applied even in emergency situations $[1-4,6]$.

To answer all questions, it is essential to know the functional and structural changes accompanied by I/R injury. Reviewing the literature, little data is available on changes in the micro-rheological parameters in relation to ischemia-reperfusion injury of extremities and ischemic conditioning surgical maneuvers.

Various models are known for unilateral hind limb ischemia, operating with vascular microvascular clips for clamping the femoral artery, tourniquet or inflated cuff around the 
thigh $[19,27-31]$. It is important to note that in rats, remarkable collaterals are existing from the gluteal region [30]. It has been demonstrated that clamping the femoral vessels alone often does not lead to complete ischemia. The tourniquet may compress collaterals as well, but the force applied may cause extended tissue damage. Most of the ischemic pre- and post-conditioning protocols use three or four cycles, the duration of which ranges from 10, 15 and $30 \mathrm{~s}$ to $10 \mathrm{~min}[13,14,18,21,22,24,32]$. We have chosen 120-min tourniquet-induced ischemia, preceded or followed by three cycles or 10-min ischemia and reperfusion.

Red blood cell deformability and aggregation show significant changes in many pathophysiological conditions, including ischemia-reperfusion injury. These are mainly due to free radical reactions, metabolic changes and acute phase reactions [20,21,33-37]. Free radicals may damage the red blood cells by lipid peroxidation, methemoglobin formation, as well as by damaging proteins via sulfhydryl cross-linking [19-21]. Metabolic changes may alter the morphological and mechanical properties of red blood cells, which leads to deterioration of red blood cell deformability and disturbed aggregation [21,36]. Acute phase reactions may manifest as a rise in leukocyte count, increase or decrease of platelet count, hemoconcentration, and micro-rheological changes [20,21,34]. Impaired red blood cell deformability and enhanced red blood cell aggregation elevate blood viscosity, increase vascular resistance, and cause perfusion problem in the microcirculatory bed $[20,21,38-41]$.

In this observational study, we found that hemoglobin and hematocrit decreased significantly after reperfusion and one week post-operatively in all ischemic groups. In parallel, the platelet count significantly increased. These changes may be associated with inflammatory processes and acute phase reactions induced by ischemia-reperfusion. The decrease in these values is due not only to I/R damage but also to blood loss caused by surgery and blood sampling. We supposed that the alterations observed post-ischemically are mostly due to redistribution changes, and the later alterations can be originated dominantly from the inflammatory processes.

Similar to our previous findings in other ischemia-reperfusion models $[25,26]$, microrheological parameters have deteriorated during and after ischemia in all ischemic groups. Red blood cell aggregation has significantly increased, mostly due to the increased free radical release, acute phase reactions, and inflammatory processes. Interestingly, the most significant increase was found in the PreC group.

Metabolic changes alter the morphological and mechanical properties of blood cells that may result in the deterioration of red blood cells' deformability and disturbed aggregation $[20,21,35,36]$. Deoxygenated red blood cells have decreased deformability and enhanced aggregation [37], while hypoxia leads to swelling of the cells, altering the cellular surface/volume ratio, and thus the deformability as well [21,36]. In our experiment, the changes in metabolic and micro-rheological parameters were not clearly observed at the same time (post-ischemic vs. first p.o. week values). Therefore, also considering the low sample size, a multivariate regression analysis could not be performed. It is also noted that mathematically significant changes could be detected, but the real in vivo significance of the magnitude in changes of micro-rheological variables are still controversial. It is still not known where the border of reversible and irreversible changes is seen, and it is still obscure whether which magnitude of red blood cell deformability impairment and/or erythrocyte aggregation enhancement causes perfusion problems [21,38-41].

During ischemia, changes in mitochondrial function, enzyme activity, and ion transport may occur. ATP is rapidly dephosphorylated and converted to AMP, which is further degraded. The ion balance of the cells is upset and the intracellular concentration of $\mathrm{H}^{+}$, $\mathrm{Na}^{+}$, and $\mathrm{Ca}^{2+}$ increases. In the process, free radicals are formed, which also cause damage to enzymes, proteins, carbohydrates, membrane lipids, and DNA. Components released from dead cells initiate inflammatory processes and release cytokines (TNF $\alpha$, IL-1 $\beta$, IL-6). Inflammatory processes may be generated and systemic inflammatory response syndrome (SIRS) may develop $[9,10]$. We harvested tissue biopsies for histological analysis, where no obvious differences were seen between the groups. The compression we used did not cause early complications. However, histological signs of I/R damage were observed in similar 
animal experiments performed at our institute. Presumably, excellent collateral circulation in the lower limb of the rat [30] reduced the degree of I/R damage we caused to such an extent that, although laboratory abnormalities developed, no histologically detected damage occurred. Ischemia laser Doppler tests confirmed the decreased microcirculatory values on the toe, but not zero values. It is supposed that the applied tourniquet did not cause complete ischemia, only hypoperfusion. The strength of the tourniquet also influences its effect, however, too strong of a compression may cause direct tissue injury, which we wanted to avoid in this model. This is a limitation of the study. We also wished to investigate the possible direct damaging effect of tourniquet applications, therefore, we got biopsies from the thigh muscles. However, in respect of the collaterals [30], examining muscles at the lower region (e.g., plantar flexor complex) would be a better choice for further future studies.

Overviewing the findings, in this study we could see that at the early reperfusion period, significant metabolic and micro-rheological changes occurred. However, their magnitude was not enough to result in visible histological alteration on standard H\&E sections. Ischemic pre-conditioning resulted in larger micro-rheological alterations than the post-conditioning protocol. These findings with post-conditioning are comparable to those of other research groups [24,32], however, the issue is still controversial. Some studies have shown its protective effect [23], but enhancement of the damage was also described [42].

Our study used healthy animals without any co-morbidities, with an intact vascular system and normovolemia. Although minimal changes have been observed without significant consequences, they had the potential to have more serious reactions. The effect of the slight changes may add up and be more significant if associated with pathological conditions (arteriosclerosis, bleeding, shock, malnutrition, etc.). There is no perfect model to study all of these aspects. All the animal studies have their own limitations, and numerous factors have to be taken into consideration when planning, conducting the studies and evaluating and extrapolating the results [31]. However, in a human study, we have found comparable results with this recent experimental study, when red blood cell deformability decreased and erythrocyte aggregation enhanced after ischemia-reperfusion by the first and second p.o. days, and non-steroid anti-inflammatory drug administration or ischemic pre-conditioning could moderate the changes in patients with lower extremity operations [43].

\section{Materials and Methods}

\subsection{Experimental Animals}

All procedures were approved and registered by the University of Debrecen Committee of Animal Welfare (permission registration Nr.: 25/2016. UDCAW) in accordance with national and EU regulations (Hungarian Animal Protection Act (Law XVIII/1998) and Directive 2010/63/EU). Thirty 8-week male Crl:WI rats were included in the experiment, and were kept in standard cages in alternating day and night light conditions in a 12-h cycle. We provided them with free access to drinking water and conventional rodent chow.

\subsection{Operative Techniques and Sampling Protocol}

The rats were anesthetized with i.p. injection of ketamine hydrochloride $(100 \mathrm{mg} / \mathrm{bwkg}$, CP-Ketamin) and xylazine (10 mg/bwkg, CP-Xylazin), combined with atropine sulfuricum $(0.05 \mathrm{mg} / \mathrm{bwkg})$. To maintain anesthesia, one third of the initial dose was administered during the procedure.

The right common carotid artery was cannulated for monitoring blood pressure in all animals. The animals were randomly divided into four groups:

I. Control (C) group $(n=8,320.4 \pm 9 \mathrm{~g})$ : besides the common carotid artery cannulation, no other intervention was performed;

II. Ischemia-reperfusion (I/R) group $(n=7,376.4 \pm 42.4 \mathrm{~g})$ : unilateral hind limb ischemia was induced by tourniquet application around the thigh, below the right inguinal 
region. After 120-min ischemia the tourniquet was completely released to allow full reperfusion;

III. Pre-conditioned (PreC) group ( $n=8,388.6 \pm 39.1 \mathrm{~g}$ ): three cycles of 10-min ischemia and reperfusion (by tightening then releasing the tourniquet, alternately) was applied before the prolonged ischemia, as described in the I/R group;

IV. Post-conditioned (PostC) group $(n=7,386.7 \pm 46 \mathrm{~g})$ : the same three cycles of ischemiareperfusion were introduced at the onset of the reperfusion, after 120-min ischemia as described in the I/R group.

The animals received flunixin meglumine s.c. $(10 \mathrm{mg} / \mathrm{bwkg})$ postoperatively.

A laser Doppler device (LD-01 Laser Doppler Tissue Flowmeter, Experimetria Co., Budapest, Hungary; with standard pencil probe MNP100XP, Oxford Optronix Ltd., Abingdon, UK) was used to test microcirculation during the ischemia to confirm ischemia or hypoperfusion. The pencil probe was taken on the skin of the right toe. Artifact-free 20-s recordings were analyzed in each animal. Blood perfusion unit values did not drop to zero, but decreased during tourniquet application versus base values (I/R group: $77.3 \pm 19.2 \%$; PreC group: $71.1 \pm 9.4 \%$; PostC group: $71 \pm 11.3 \%$ ).

During the experiment, blood samples were taken from the lateral tail vein at the beginning of the procedure (before the 120-min ischemia, as Base), then after the removal of the tourniquet at the beginning of reperfusion, in group IV after the post-conditioning, and one week later in all groups. In the Control group, the timing of the second blood sampling was set $120 \mathrm{~min}$ after the preparation and cannulation. Occasionally, 0.3 to $0.5 \mathrm{~mL}$ of blood was taken (anticoagulant: $1.8 \mathrm{mg} / \mathrm{mL} \mathrm{K}_{3}$-EDTA). Histological samples were taken from the ischemic muscle one week after the intervention.

\subsection{Laboratory Methods}

Hematological parameters were determined by a Sysmex K-4500 microcell counter (TOA Medical Electronics Co., Ltd., Kobe, Japan). Red blood cell count $\left(\mathrm{RBC}\left[\times 10^{6} / \mathrm{L}\right]\right)$, hematocrit $(\mathrm{Hct}[\%])$, hemoglobin $(\mathrm{Hgb}[\mathrm{g} / \mathrm{dL}])$, white blood cell count $\left(\mathrm{WBC}\left[\times 10^{3} / \mathrm{L}\right]\right)$, and platelet count $\left(\mathrm{Plt}\left[\times 10^{3} / \mathrm{L}\right]\right)$ were analyzed in this study.

A LoRRca MaxSis Osmoscan (RR Mechatronics BV, Zwaag, The Netherlands) ektacytometer was used to test red blood cell deformability, determining the elongation index (EI [au]) in the function of shear stress (SS [Pa]) [44,45]. For the tests polyvinylpyrrolidone (PVP), normal phosphate buffered saline (PBS) solution was prepared (PVP: 360 kDa, Sigma-Aldrich Co., St. Luis, MO, USA; PVP-PBS solution viscosity $=29.5 \mathrm{~m}$ Pas, osmolality $=300 \mathrm{mOsmol} / \mathrm{kg}$, $\mathrm{pH}=7.2$ ). For comparison, the EI values at $3 \mathrm{~Pa}$ of shear stress, and by parameterization of EI-SS curves (Lineweaver-Burk equation), maximal elongation index ( $\left.\mathrm{EI}_{\max }\right)$, the shear stress belonging to the half $\mathrm{EI}_{\max }\left(\mathrm{SS}_{1 / 2},[\mathrm{~Pa}]\right)$, and their ratio were calculated [46].

To measure red blood cell aggregation in whole blood, we used a Myrenne MA-1 erythrocyte aggregometer (Myrenne $\mathrm{GmbH}$, Roetgen, Germany), based on the lighttransmission principle [44,45]. Aggregation was tested in $M$ (shear rate $=0 \mathrm{~s}^{-1}$ ) and M1 modes (shear rate $=3 \mathrm{~s}^{-1}$ ) at the 5th and 10th seconds, accordingly, the M 5s, M 10s, M1 5s and M1 10s index parameters were determined.

An epoc ${ }^{\circledR}$ Blood Analysis System (Siemens Healthineers, Erlangen, Germany) was used to test blood partial oxygen and carbon-dioxide tensions $\left(\mathrm{O}_{2}, p \mathrm{CO}_{2}[\mathrm{mmHg}]\right)$, blood $\mathrm{pH}$, electrolytes $\left(\mathrm{Na}^{+}, \mathrm{K}^{+}, \mathrm{Ca}^{2+}\right.$ and $\mathrm{Cl}^{-}$) and metabolites (glucose [mmol/L], lactate $[\mathrm{mmol} / \mathrm{L}]$, creatinine $[\mu \mathrm{mol} / \mathrm{L}])$. The test card (per sample) required $0.1 \mathrm{~mL}$ of native blood.

\subsection{Histology}

One week postoperatively, tissue samples were taken from the biceps femoris muscle under general anesthesia. The samples were fixed in 5\% formaldehyde, embedded in paraffin, microtomed into 3-5 $\mu \mathrm{m}$ sections, stained with hematoxylin and eosin (H\&E), and evaluated under an optical microscope. 


\subsection{Statistical Analysis}

Data are expressed as means \pm standard deviation (S.D.). In case of variables when the base values showed high variety, we also analyzed the ratio of changes (relative values vs. its own base in each case). A GraphPad Prism software for Windows, version 8.0 (GraphPad Software Inc., La Jolla, CA, USA) was used for statistical analysis. Differences within and between the groups were analyzed by two-way ANOVA followed by post-hoc Bonferroni-test or Dunn's method, depending on the result of normality test. Probability values $(p)$ less than 0.05 were considered as statistically significantly different.

\section{Conclusions}

In conclusion, 2-h tourniquet-induced hind limb ischemia and reperfusion caused impairment in red blood cell deformability with enhanced erythrocyte aggregation, accompanied by hematological and metabolic changes promptly after ischemia. Ischemic preand post-conditioning $(3 \times 10$-min ischemia with 10 -min reperfusion periods prior or after 120-min ischemia) resulted in additive changes of various manners. Post-conditioning showed better micro-rheological effects. However, by these parameters, it cannot be clearly decided which ischemic conditioning protocol is better. Using a longer limb ischemic period ( 3 or $4 \mathrm{~h}$, with, e.g., vascular clamping plus tourniquet application) would be recommended to use for better studying this issue.

Author Contributions: Conceptualization, C.K., K.P. and N.N.; methodology, investigation, C.K., B.S., A.D. and E.V.; sample preparation, laboratory and histological investigations, A.V., B.B., Z.H., I.K.; data analysis, C.K., A.V., A.D. and N.N.; writing-original draft preparation, C.K., N.N. and K.P.; writing - review and editing, K.P. and N.N.; supervision, N.N. and K.P.; funding acquisition, N.N. All authors have read and agreed to the published version of the manuscript.

Funding: The work was supported by the Bridging Fund of the Faculty of Medicine, University of Debrecen and the National Research, Development and Innovation Office (NKFI-1 "OTKA" K-139184).

Institutional Review Board Statement: The animal experiments were registered and approved by the University of Debrecen Committee of Animal Welfare and by the National Food Chain Safety Office (registration Nr. 25/2016/UDCAW) in accordance with the national (Act XXVIII of 1998 on the protection and sparing of animals) and EU (Directive 2010/63/EU) regulations.

Informed Consent Statement: Not applicable.

Data Availability Statement: The data presented in this study are available on request from the corresponding author.

Acknowledgments: Authors are grateful to the staff of the Department of Operative Techniques and Surgical Research, Faculty of Medicine, University of Debrecen.

Conflicts of Interest: The authors declare no conflict of interest.

\section{References}

1. Santistevan, J.R. Acute limb ischemia: An emergency medicine approach. Emerg. Med. Clin. N. Am. 2017, 35, 889-909. [CrossRef]

2. Olinic, D.M.; Stanek, A.; Tataru, D.A.; Homorodean, C.; Olinic, M. Acute limb ischemia: An update on diagnosis and management. J. Clin. Med. 2019, 8, 1215. [CrossRef]

3. Naito, H.; Nojima, T.; Fujisaki, N.; Tsukahara, K.; Yamamoto, H.; Yamada, T.; Aokage, T.; Yumoto, T.; Osako, T.; Nakao, A. Therapeutic strategies for ischemia reperfusion injury in emergency medicine. Acute Med. Surg. 2020, 7, e501. [CrossRef]

4. Natarajan, B.; Patel, P.; Mukherjee, A. Acute lower limb ischemia-etiology, pathology, and management. Int. J. Angiol. 2020, 29, 168-174. [CrossRef]

5. Walker, A.C.; Johnson, N.J. Critical care of the post-cardiac arrest patient. Cardiol. Clin. 2018, 36, 419-428. [CrossRef]

6. De Groot, H.; Rauen, U. Ischemia-reperfusion injury: Processes in pathogenetic networks: A review. Transplant. Proc. 2007, 39, 481-484. [CrossRef]

7. Mustoe, T. Understanding chronic wounds: A unifying hypothesis on their pathogenesis and implications for therapy. Am. J. Surg. 2004, 187, 65S-70S. [CrossRef]

8. Eckert, P.; Schnackerz, K. Ischemic tolerance of human skeletal muscle. Ann. Plast. Surg. 1991, 26, 77-84. [CrossRef] 
9. Blaisdell, F.W. The pathophysiology of skeletal muscle ischemia and the reperfusion syndrome: A review. Cardiovasc. Surg. 2002, 10, 620-630. [CrossRef]

10. Eltzschig, H.; Eckle, T. Ischemia and reperfusion-From mechanism to translation. Nat. Med. 2011, 17, 1391-1401. [CrossRef]

11. Gillani, S.; Cao, J.; Suzuki, T.; Hak, D.J. The effect of ischemia reperfusion injury on skeletal muscle. Injury 2012, 43, 670-675. [CrossRef] [PubMed]

12. Okamoto, F.; Allen, B.S.; Buckberg, G.D.; Bugyi, H.; Leaf, J. Reperfusion conditions: Importance of ensuring gentle versus sudden reperfusion during relief of coronary occlusion. J. Thorac. Cardiovasc. Surg. 1986, 92, 613-620. [CrossRef]

13. Murry, C.E.; Jennings, R.B.; Reimer, K.A. Preconditioning with ischemia: A delay of lethal cell injury in ischemic myocardium. Circulation 1986, 74, 1124-1136. [CrossRef]

14. Pasupathy, S.; Homer-Vanniasinkam, S. Surgical implications of ischemic preconditioning. Arch. Surg. 2005, 140, 405-409. [CrossRef]

15. Ulus, A.T.; Yavas, S.; Sapmaz, A.; Sakaoğullari, Z.; Simsek, E.; Ersoz, S.; Koksoy, C. Effect of conditioning on visceral organs during indirect ischemia/reperfusion injury. Ann. Vasc. Surg. 2014, 28, 437-444. [CrossRef]

16. Przyklenk, K.; Bauer, B.; Ovize, M.; Kloner, R.A.; Whittaker, P. Regional ischemic 'preconditioning' protects remote virgin myocardium from subsequent sustained coronary occlusion. Circulation 1993, 87, 893-899. [CrossRef]

17. Zhang, Y.; Liu, X.R.; Yan, F.; Min, L.Q.; Ji, X.M.; Luo, Y.M. Protective effects of remote ischemic preconditioning in rat hindlimb on ischemia- reperfusion injury. Neural Regen. Res. 2012, 7, 583-587.

18. Zhao, Z.Q.; Corvera, J.S.; Halkos, M.E.; Kerendi, F.; Wang, N.P.; Guyton, R.A.; Vinten-Johansen, J. Inhibition of myocardial injury by ischemic postconditioning during reperfusion: Comparison with ischemic preconditioning. Am. J. Physiol. Heart Circ. Physiol. 2003, 285, H579-H588. [CrossRef]

19. Kayar, E.; Mat, F.; Meiselman, H.J.; Baskurt, O.K. Red blood cell rheological alterations in a rat model of ischemia-reperfusion injury. Biorheology 2001, 38, 405-414.

20. Baskurt, O.K. Mechanisms of blood rheology alterations. In Handbook of Hemorheology and Hemodynamics; Baskurt, O.K., Hardeman, M.R., Rampling, M.W., Meiselman, H.J., Eds.; IOS Press: Amsterdam, The Netherlands, 2007; pp. 170-190.

21. Nemeth, N.; Peto, K.; Magyar, Z.; Klarik, Z.; Varga, G.; Oltean, M.; Mantas, A.; Czigany, Z.; Tolba, R.H. Hemorheological and microcirculatory factors in liver ischemia-reperfusion injury-An update on pathophysiology, molecular mechanisms and protective strategies. Int. J. Mol. Sci. 2021, 22, 1864. [CrossRef]

22. McAllister, S.E.; Ashrafpour, H.; Cahoon, N.; Huang, N.; Moses, M.A.; Neligan, P.C.; Forrest, C.R.; Lipa, J.E.; Pang, C.Y. Postconditioning for salvage of ischemic skeletal muscle from reperfusion injury: Efficacy and mechanism. Am. J. Physiol. Regul. Integr. Comp. Physiol. 2008, 295, R681-R689. [CrossRef] [PubMed]

23. Park, J.W.; Kang, J.W.; Jeon, W.J.; Na, H.S. Postconditioning protects skeletal muscle from ischemia-reperfusion injury. Microsurgery 2010, 30, 223-229. [CrossRef]

24. Lintz, J.A.; Dalio, M.B.; Joviliano, E.E.; Piccinato, C.E. Ischemic pre and postconditioning in skeletal muscle injury produced by ischemia and reperfusion in rats. Acta Cir. Bras. 2013, 28, 441-446. [CrossRef] [PubMed]

25. Magyar, Z.; Mester, A.; Nadubinszky, G.; Varga, G.; Ghanem, S.; Somogyi, V.; Tanczos, B.; Deak, A.; Bidiga, L.; Oltean, M.; et al. Beneficial effects of remote organ ischemic preconditioning on micro-rheological parameters during liver ischemia-reperfusion in the rat. Clin. Hemorheol. Microcirc. 2018, 70, 181-190. [CrossRef]

26. Varga, G.; Ghanem, S.; Szabo, B.; Nagy, K.; Pal, N.; Tanczos, B.; Somogyi, V.; Barath, B.; Deak, A.; Peto, K.; et al. Renal ischemiareperfusion-induced metabolic and micro-rheological alterations and their modulation by remote organ ischemic preconditioning protocols in the rat. Clin. Hemorheol. Microcirc. 2019, 71, 225-236. [CrossRef] [PubMed]

27. Nemeth, N.; Szokoly, M.; Acs, G.; Brath, E.; Lesznyak, T.; Furk, I.; Miko, I. Systemic and regional hemorheological consequences of warm and cold hind limb ischemia-reperfusion in a canine model. Clin. Hemorheol. Microcirc. 2004, 30, $133-145$.

28. Nemeth, N.; Lesznyak, T.; Szokoly, M.; Furka, I.; Miko, I. Allopurinol prevents erythrocyte deformability impairing but not the hematological alterations after limb ischemia-reperfusion in rats. J. Investig. Surg. 2006, 19, 47-56. [CrossRef]

29. Nemeth, N.; Kiss, F.; Hever, T.; Brath, E.; Sajtos, E.; Furka, I.; Miko, I. Hemorheological consequences of hind limb ischemiareperfusion differs in normal and gonadectomized male and female rats. Clin. Hemorheol. Microcirc. 2012, 50, 197-211. [CrossRef]

30. Rosero, O.; Nemeth, K.; Turoczi, Z.; Fulop, A.; Garbaisz, D.; Gyorffy, A.; Szuak, A.; Dorogi, B.; Kiss, M.; Nemeskeri, A.; et al. Collateral circulation of the rat lower limb and its significance in ischemia-reperfusion studies. Surg. Today 2014, 44, $2345-2353$. [CrossRef]

31. Nemeth, N.; Deak, A.; Szentkereszty, Z.; Peto, K. Effects and influencing factors on hemorheological variables taken into consideration in surgical pathophysiology research. Clin. Hemorheol. Microcirc. 2018, 69, 133-140. [CrossRef] [PubMed]

32. Kocman, E.A.; Ozatik, O.; Sahin, A.; Guney, T.; Kose, A.A.; Dag, I.; Alatas, O.; Cetin, C. Effects of ischemic preconditioning protocols on skeletal muscle ischemia-reperfusion injury. J. Surg. Res. 2015, 193, 942-952. [CrossRef] [PubMed]

33. Johnson, R.M. pH effects on red blood cell deformability. Blood Cells. 1985, 11, 317-321. [PubMed]

34. Koppensteiner, R. Blood rheology in emergency medicine. Semin. Thromb. Hemost. 1996, 22, 89-91. [CrossRef]

35. Reinhart, W.H.; Gaudenz, R.; Walter, R. Acidosis induced by lactate, pyruvate, or $\mathrm{HCl}$ increases blood viscosity. Crit. Care 2002, 17, 38-42. [CrossRef] [PubMed]

36. Cicha, I.; Suzuki, Y.; Tateishi, N.; Maeda, N. Changes of RBC aggregation in oxygenation-deoxygenation: pH dependency and cell morphology. Am. J. Physiol. Heart Circ. Physiol. 2003, 284, H2335-H2342. [CrossRef] 
37. Uyuklu, M.; Meiselman, H.J.; Baskurt, O.K. Effect of hemoglobin oxygenation level on red blood cell deformability and aggregation parameters. Clin. Hemorheol. Microcirc. 2009, 41, 179-188. [CrossRef]

38. Lipowsky, H.H. Microvascular rheology and hemodynamics. Microcirculation 2005, 12, 5-15. [CrossRef]

39. Pries, A.R.; Secomb, T.W. Blood flow in microvascular networks. In Handbook of Physiology, Microcirculation, 2nd ed.; Tuma, R.F., Duran, W.N., Ley, K., Eds.; Elsevier Academic Press: Amsterdam, The Netherlands, 2008; pp. 3-36.

40. Chandran, K.B.; Rittgers, S.E.; Yoganathan, A.P. Rheology of blood and vascular mechanics. In Biofluid Mechanics; Chandran, K.B., Rittgers, S.E., Yoganathan, A.P., Eds.; CRC Press: Boca Raton, FL, USA, 2012; pp. 109-154.

41. Baskurt, O.K. In vivo correlates of altered blood rheology. Biorheology 2008, 45, 629-638. [CrossRef]

42. Schoen, M.; Rotter, R.; Gierer, P.; Gradl, G.; Strauss, U.; Jonas, L.; Mittlmeier, T.; Vollmar, B. Ischemic preconditioning prevents skeletal muscle tissue injury, but not nerve lesion upon tourniquet-induced ischemia. J. Trauma 2007, 63, 788-797. [CrossRef]

43. Turchanyi, B.; Korei, C.; Somogyi, V.; Kiss, F.; Peto, K.; Nemeth, N. Beneficial postoperative micro-rheological effects of intraoperative administration of diclophenac or ischemic preconditioning in patients with lower extremity operations-Preliminary data. Clin. Hemorheol. Microcirc. 2021; Epub ahead of print. [CrossRef]

44. Hardeman, M.; Goedhart, P.; Shin, S. Methods in hemorheology. In Handbook of Hemorheology and Hemodynamics; Baskurt, O.K., Hardeman, M.R., Rampling, M.W., Meiselman., H.J., Eds.; IOS Press: Amsterdam, The Netherlands, 2007; pp. $242-266$.

45. Baskurt, O.K.; Boynard, M.; Cokelet, G.C.; Connes, P.; Cooke, B.M.; Forconi, S.; Liao, F.; Hardeman, M.R.; Jung, F.; Meiselman, H.J.; et al. International Expert Panel for Standardization of Hemorheological Methods. New guidelines for hemorheological laboratory techniques. Clin. Hemorheol. Microcirc. 2009, 42, 75-97. [CrossRef] [PubMed]

46. Baskurt, O.K.; Hardeman, M.R.; Uyuklu, M.; Ulker, P.; Cengiz, M.; Nemeth, N.; Shin, S.; Alexy, T.; Meiselman, H.J. Parameterization of red blood cell elongation index-Shear stress curves obtained by ektacytometry. Scand. J. Clin. Lab. Investig. 2009, 69, 777-788. [CrossRef] [PubMed] 